\title{
Combination treatment with quercetin and resveratrol attenuates high fat diet-induced obesity and associated inflammation in rats via the AMPKo1/SIRT1 signaling pathway
}

\author{
LE ZHAO $^{1 *}$, FANG CEN $^{1 *}$, FENG TIAN ${ }^{2 *}$, MIN-JIE LI ${ }^{2}$, QI ZHANG ${ }^{2}$, HONG-YI SHEN $^{3}$, \\ $\mathrm{XIANG}-\mathrm{CHUN} \mathrm{SHEN}^{4}$, MING-MEI ZHOU ${ }^{1}$ and JUN DU ${ }^{2}$
}

\begin{abstract}
${ }^{1}$ Center for Chinese Medicine Therapy and Systems Biology, Interdisciplinary Science Research Institute, Shanghai University of Traditional Chinese Medicine; ${ }^{2}$ Nutrilite Health Institute; ${ }^{3}$ Research Center for Health and Nutrition, School of Public Health, Shanghai University of Traditional Chinese Medicine, Shanghai 201203; ${ }^{4}$ The High Educational

Key Laboratory of Guizhou for Natural Medicinal Pharmacology and Drugability, School of

Pharmaceutical Science, Guizhou Medical University, Huaxi, Guizhou 550025, P.R. China
\end{abstract}

Received February 3, 2017; Accepted July 27, 2017

DOI: $10.3892 / \mathrm{etm} .2017 .5331$

\begin{abstract}
Diet-induced obesity is associated with systemic inflammation, which is considered to originate predominantly from the adipose tissue. Quercetin and resveratrol are two dietary polyphenols that exhibit anti-inflammatory properties and anti-insulin resistance when administered in isolation or combination (CQR). It remains unknown whether $\mathrm{CQR}$ reduces high fat diet (HFD)-induced obesity and inflammation in rats. In the current study, 46 male Wistar rats were divided into two groups, one of which was fed a normal diet (ND, $5.4 \%$ fat, w/w) and one of which was fed a HFD (45\% fat, w/w) for 3 weeks. Following removal of the 12 most obesity-resistant rats from the HFD group, the remaining rats were divided into two sub-groups: A HFD group and a HFD+CQR group (administered $120 \mathrm{mg} / \mathrm{kg} /$ day resveratrol and $240 \mathrm{mg} / \mathrm{kg} /$ day quercetin). The results revealed that the HFD+CQR group had significantly lower body weights at 11 weeks compared with the HFD group and had significantly reduced visceral adipose tissue weights and adipocyte sizes. Serum lipid profiles were also significantly ameliorated in the HFD+CQR group. $\mathrm{CQR}$
\end{abstract}

Correspondence to: Professor Ming-Mei Zhou, Center for Chinese Medicine Therapy and Systems Biology, Interdisciplinary Science Research Institute, Shanghai University of Traditional Chinese Medicine, 1200 Cailun Road, Shanghai 201203, P.R. China

E-mail: zhoumm368@163.com

Dr Jun Du, Nutrilite Health Institute, 720-6 Cailun Road, Pudong, Shanghai 201203, P.R. China

E-mail: eric.du@amway.com

*Contributed equally

Key words: quercetin, resveratrol, high-fat diet, inflammation, 5 -adenosine monophosphate-activated protein kinase catalytic subunit $\alpha-1$, sirtuin 1 attenuated the expression of systemic proinflammatory adipokines, including leptin, tumor necrosis factor- $\alpha$, monocyte chemoattractant protein-1 and interleukin-6. It also reduced the recruitment of mast cells to the epididyotic adipose tissue (EAT). Furthermore, CQR reversed the HFD-induced suppression of 5'-adenosine monophosphate-activated protein kinase $\alpha 1$ (AMPK $\alpha 1)$ phosphorylation and sirtuin 1 (SIRT1) expression in EAT. In conclusion, CQR may suppress obesity and associated inflammation via the AMPK $\alpha 1 /$ SIRT1 signaling pathway in rats fed a HFD.

\section{Introduction}

Obesity-induced systemic inflammation originates in adipose tissue prior to hepatic tissue $(1,2)$. The human body contains various fat deposits, which can be divided into white and brown fat. White adipose tissue (WAT) is a multifunctional organ that stores nutrients in the form of fat droplets. In addition, WAT secretes cytokines that affect the body's metabolic state, thus it is sometimes regarded as the largest endocrine organ in the body (3). Excessive energy intake induces adipocyte hypertrophy and hyperplasia, which may lead to the development of high fat diet-induced obesity. Hypertrophic adipocytes release chemokines and proinflammatory cytokines to activate and attract inflammatory cells into WAT. This contributes to systemic insulin resistance and ultimately, a state of chronic low-grade adipose tissue inflammation (4). Polyphenol intake is positively associated with a decrease in the incidence of metabolic and obesity-associated disorders. Quercetin is a polyphenolic flavonoid compound present in a variety of fruits and vegetables, including onions, broccoli, tomatoes, apples and berries. It has a wide range of biological activities and health-promoting effects, including anti-carcinogenic (5), antiviral (6), antioxidant (7), antidiabetic (8), anti-inflammatory (9), anti-aging (10) and angioprotective properties (11). Furthermore, it has recently been suggested that quercetin exerts anti-obesity activity via the mitogen-activated protein kinase (MAPK) and 5'-adenine 
monophosphate-activated protein kinase $\alpha 1$ (AMPK $\alpha 1)$ signaling pathways (12). Resveratrol, a phytoalexin found in the skin and seeds of grapes and in red wine, may also protect against diet-induced obesity and metabolic diseases including hepatic steatosis and insulin resistance (13). In the present study, the effect of combination treatment with quercetin and resveratrol (CQR) was investigated in rats fed a HFD. The impact on CQR on HFD-induced fat accumulation, insulin resistance, proinflammatory cytokine levels, mast infiltration and AMPK $\alpha 1 /$ sirtuin 1 (SIRT1) signaling in adipose tissues was assessed.

\section{Materials and methods}

Animals. The present study was approved by the Institutional Animal Care and Use Committee of Shanghai University of Traditional Chinese Medicine (Shanghai, China), and all procedures were performed in accordance with the National Institute of Health's guidelines (14). A total of 46 male 8 -week-old Wistar rats with a mean weight of $200 \pm 10 \mathrm{~g}$ were provided by the Shanghai SLAC Laboratory Animal Co., Ltd. (Shanghai, China). Rats were raised in an environment of $22 \pm 0.5^{\circ} \mathrm{C}$ and $40-70 \%$ relative humidity under a $12 \mathrm{~h}$ light/dark cycle, with food and water freely available. Following 1-week habituation, the rats were randomly divided into 2 groups. The normal diet (ND) group, $(n=10)$ were fed a regular chow diet containing $5.4 \%$ fat and the HFD group, $(n=36)$ were fed a HFD containing $45 \%$ fat. After 3 weeks, rats in the HFD group were ranked according to weight gain, and rats in the lower third $(n=12)$ were excluded from the study as they were deemed to be obesity resistant. The remaining 24 rats in the HFD group were randomly divided into 2 sub-groups: i) A HFD group $(n=12)$; and ii) a HFD+CQR $(n=12)$ group. CQR treatment consisted of $120 \mathrm{mg} / \mathrm{kg} / \mathrm{day}$ resveratrol (purity, $\geq 98 \%$; Hangzhou Great Forest Biomedical Co., Ltd., Hangzhou, China) and $240 \mathrm{mg} / \mathrm{kg} /$ day quercetin (purity $\geq 98$; Nanjing Zelang Medical Technology Co., Ltd., Nanjing, China) The body weight and food intake of the rats was recorded each week. After 11 weeks, rats were anesthetized with isoflurane and sacrificed following a $12 \mathrm{~h}$ fast. Blood was extracted from the abdominal aorta and centrifuged at 5,000 $\mathrm{x} g$ for $15 \mathrm{~min}$ at $4^{\circ} \mathrm{C}$. The serum was separated and stored at $-80^{\circ} \mathrm{C}$ prior to analysis. Following blood collection, subcutaneous adipose tissues (SATs), epididymis adipose tissues (EATs) and perinephric adipose tissues were promptly removed, rinsed, weighed on ice and then snap frozen in liquid nitrogen and stored at $-80^{\circ} \mathrm{C}$.

Biochemical parameters. Total cholesterol (C), triglycerides (TG), high-density lipoprotein-C (HDL-C) and low-density lipoprotein-C (LDL-C) in the serum were measured and quantified using a Hitachi 7600 automatic biochemical analyzer (Hitachi, Ltd., Tokyo, Japan) with the corresponding kits as follows: Quick Auto Neo T-CHOLII assay reagent and Quick Auto Neo TGII assay reagent, manufactured by Shino-Test Corporation (Tokyo, Japan); L-type HDL-C reagent 1 (cat no. 998-09011), reagent 2 (cat no. 994-09111); and L-type LDL-C reagent 1 (cat no. 997-39893) and reagent 2, (cat no. 993-39993), manufactured by Wako Pure Chemical Industries, Ltd. (Osaka, Japan).
Cytokine quantification. Levels of leptin, adiponectin, insulin, interleukin-6 (IL-6), tumor necrosis factor- $\alpha$ (TNF- $\alpha$ ) and monocyte chemotactic protein-1 (MCP-1) in the serum were quantified using the corresponding commercial rat ELISA kits as follows: Rat leptin, LEP ELISA kit (cat no. CSB-E07433r); rat adiponectin, ADP ELISA kit, (cat no. CSB-E07271r); rat insulin, INS ELISA kit (CSB-E05070r); rat IL-6, IL-6 ELISA kit (cat no. CSB-E04640r); rat TNF- $\alpha$ ELISA kit (cat no. CSB-E11987r); and rat MCP-1/monocyte chemotactic and activating factor, MCP-1/MCAF ELISA kit (cat no. CSB-E07429r; Cusabio Biotech Co., Ltd., Wuhan, China) according to the manufacturer's protocols.

Histopathology. Adipose tissues were collected at 11 weeks and fixed in $4 \%$ formalin at room temperature for $24 \mathrm{~h}$, embedded in paraffin and sliced serially into sections $5-\mu \mathrm{m}$ thick. To determine adipocyte size, hematoxylin and eosin staining was conducted on EATs at room temperature for $30 \mathrm{~min}$. Five visual fields were randomly selected from each section with an Olympus BX51 light microscope (Olympus Corporation, Tokyo, Japan) and examined using Image-Pro Plus version 6.0 (Media Cybernetics, Inc., Rockville, MD, USA) to determine the average adipocyte diameter. Toluidine blue staining was also performed on EATs for $1 \mathrm{~h}$ by briefly submerging tissue sections in $0.1 \%$ aqueous toluidine blue (Sigma-Aldrich; Merck KGaA, Darmstadt, Germany) at room temperature, the histological images were used to quantify the number of mast cells present, as previously described (15). Mast cell numbers were counted using a light microscope and were presented as cell numbers $/ \mathrm{mm}^{2}$.

Protein extraction and western blot analysis. Plasma membrane proteins were extracted from adipose tissues using a radioimmunoprecipitation assay lysis buffer (cat no. 89900, Pierce; Thermo Fisher Scientific, Inc., Waltham, MA, USA), total protease inhibitor and phosphatase inhibitor, as described previously (16). Protein concentration was measured using a commercial bicinchoninic acid assay kit and a microplate reader at $570 \mathrm{~nm}$. Subsequently protein (40 $\mu \mathrm{g} /$ lane) was separated by $10 \%$ SDS-PAGE and transferred to a polyvinylidene difluoride membrane (Bio-Rad Laboratories, Inc., Hercules, CA, USA). The membranes were blocked with $2 \%$ bovine serum albumin (cat no. K720; Ameresco, Inc., Framingham, MA, USA) at room temperature and TBS with Tween-20 for $1 \mathrm{~h}$, then incubated overnight at $4^{\circ} \mathrm{C}$ with AMPK $\alpha 1$ antibody (cat no. 2795), phosphorylated (p)-AMPK $\alpha 1$ (Thr172; cat no. 2535), or SIRT1 rabbit monoclonal antibodies (cat no 3931). Membranes were also incubated with monoclonal mouse anti-human $\beta$-actin antibody (cat no. 4967; all 1:1,000 dilution; all from Cell Signalling Technology, Inc., Danvers, MA, USA) as the loading control. Following extensive washing in Tween-PBS, membranes were incubated with horseradish peroxidase-conjugated goat anti-rabbit immunoglobulin $\mathrm{G}$ antibody (1:4,000; cat no. sc-2030; Santa Cruz Biotechnology, Inc., Dallas, TX, USA) for $1 \mathrm{~h}$. Bands were visualized using LightShift $^{\mathrm{TM}}$ Chemiluminescent electrophoretic mobility shift assay kit (cat no. 20148; Thermo Fisher Scientific, Inc.) and the ImageQuant $^{\mathrm{TM}}$ LAS 4000 Mini, quantified using ImageQuant TL 7.0 software (both from GE Healthcare, Chicago, IL, USA) and expressed as the ratio of pAMPK $\alpha 1$ to AMPK $\alpha 1$ or SIRT1 to $\beta$-actin. 


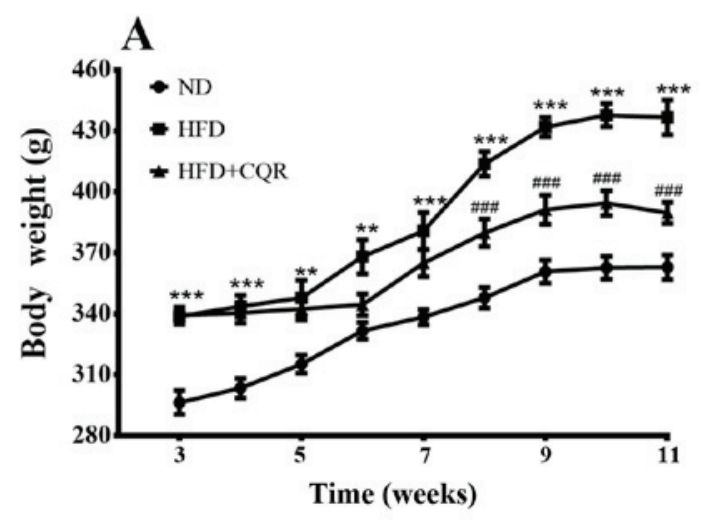

C

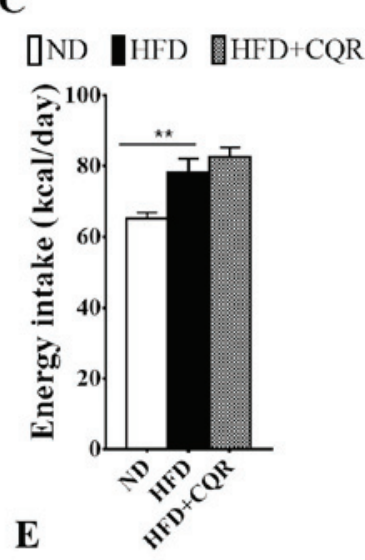

D

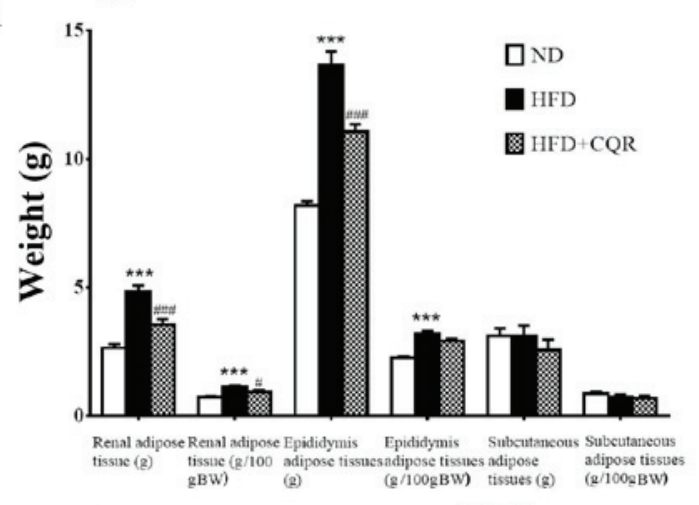

ND
B

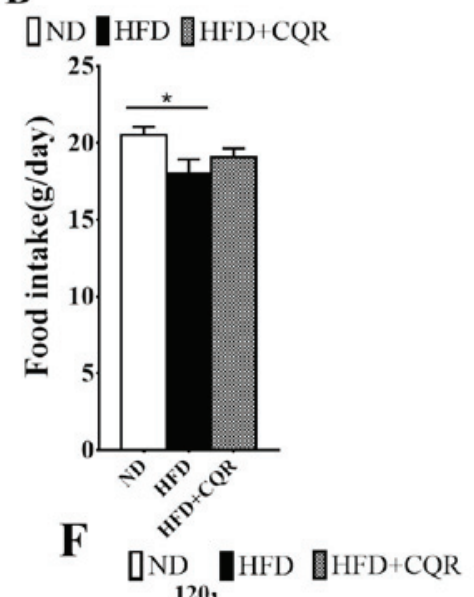

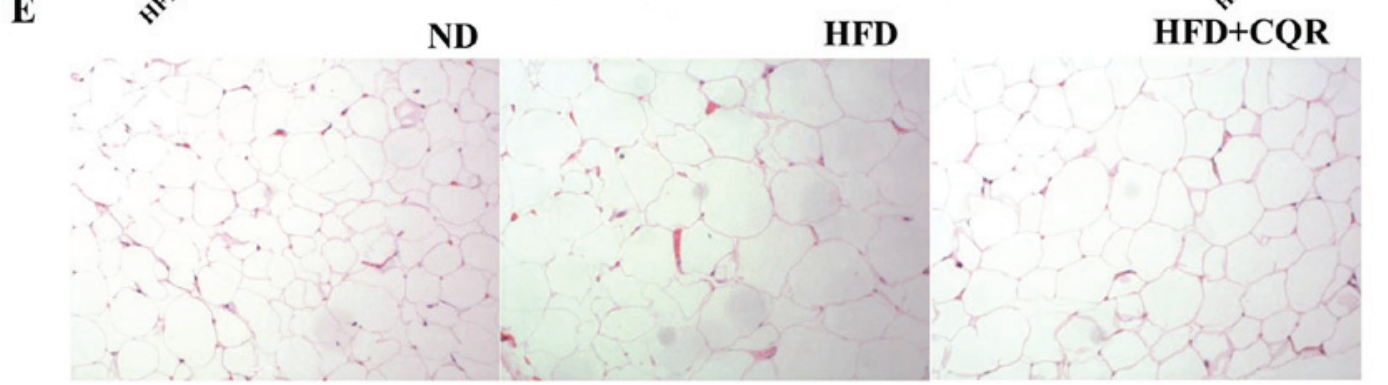

Figure 1. Treatment with CQR reduces the body and visceral fat weights of rats fed a HFD. Rats were fed a ND, a HFD or a HFD+CQR for a period of 11 weeks. Subsequently (A) body weight, (B) food intake, (C) energy intake and (D) white adipose tissue weights were measured. (E) EAT morphology was observed using a light microscope at a magnification of $\mathrm{x} 200$ and the $(\mathrm{F})$ adipocyte diameters in EAT were measured. Data are expressed as the mean \pm standard error of mean. ${ }^{*} \mathrm{P}<0.05,{ }^{* * *} \mathrm{P}<0.01$ and ${ }^{* * *} \mathrm{P}<0.001$ vs. ND. ${ }^{\#} \mathrm{P}<0.05$ and ${ }^{\# \# "} \mathrm{P}<0.001$ vs. HFD. CQR, combination of quercetin and resveratrol; HFD, high fat diet; ND, normal diet; EAT, epididymal adipose tissues.

Statistical analysis. All data are presented as the mean \pm standard error of the mean. For multiple comparisons, differences were analyzed using one-way analysis of variance followed by Tukey's multiple comparison test. $\mathrm{P}<0.05$ was considered to indicate a statistically significant difference. All statistics were analyzed using Graphpad Prism version 6.0 (GraphPad Software, Inc., La Jolla, CA, USA).

\section{Results}

Treatment with CQR results in a lower body and visceral adipose tissue weight in an HFD-rat model. After 3 weeks, at the point of CQR intervention, the body weight of rats in the HFD group was significantly higher than those in the ND group (Fig. 1A). The body weight increase was alleviated by CQR between weeks 8 and 11 and following 11 weeks intervention; HFD+CQR rats had a significantly lower body weight than HFD rats (Fig. 1A). Food intake was significantly lower in HFD rats compared with ND rats (Fig. 1B), however energy intake was significantly higher (Fig. 1C). CQR did not exert a marked effect on food and energy intake. At the end of week 11, HFD+CQR rats had a notably lower visceral (epididymal and perirenal) adipose tissue weight (Fig. 1D) and a significantly smaller adipose cell diameter compared with the HFD group (Fig. 1E and F). Subcutaneous adipose tissue weight did not differ significantly across all groups (Fig. 1D). These results suggest that CQR treatment may inhibit HFD-induced obesity.

CQR treatment affects lipid levels in the serum. The HFD group exhibited significantly higher levels of total C, TG and LDL-C in the serum compared with the ND group (Table I). CQR significantly attenuated these lipid levels compared with the HFD. However, CQR did not reverse the decrease in serum HDL-C induced by HFD (Table I). 
Table I. CQR normalizes the concentrations of serum constituents in HFD fed rats.

\begin{tabular}{lccc}
\hline Parameter & ND & HFD & HFD+CQR \\
\hline Serum total C $(\mu \mathrm{mol} / \mathrm{l})$ & $1536 \pm 101.5^{\mathrm{a}}$ & $1987 \pm 100.6$ & $1587 \pm 70.36^{\mathrm{a}}$ \\
Serum TG $(\mu \mathrm{mol} / \mathrm{l})$ & $685.8 \pm 89.93^{\mathrm{c}}$ & $1366 \pm 129.3$ & $746.4 \pm 80.98^{\mathrm{c}}$ \\
Serum HDL-C $(\mu \mathrm{mol} / \mathrm{l})$ & $1010 \pm 24.72^{\mathrm{b}}$ & $778.3 \pm 30.79$ & $901.7 \pm 23.09$ \\
Serum LDL-C $(\mu \mathrm{mol} / \mathrm{l})$ & $275.0 \pm 13.76^{\mathrm{b}}$ & $462.5 \pm 29.39$ & $305.0 \pm 31.66^{\mathrm{b}}$ \\
Serum insulin $(\mathrm{IU} / \mathrm{ml})$ & $66.66 \pm 4.422^{\mathrm{a}}$ & $84.65 \pm 4.917$ & $68.16 \pm 3.454^{\mathrm{a}}$ \\
Serum leptin $(\mathrm{pg} / \mathrm{ml})$ & $542.5 \pm 27.07^{\mathrm{c}}$ & $904.2 \pm 47.88$ & $667.7 \pm 36.90^{\mathrm{c}}$ \\
Serum adiponectin $(\mathrm{pg} / \mathrm{ml})$ & $68.78 \pm 4.889^{\mathrm{a}}$ & $38.74 \pm 3.740$ & $60.70 \pm 3.934$ \\
Serum TNF- $\alpha(\mathrm{pg} / \mathrm{ml})$ & $41.50 \pm 6.000^{\mathrm{b}}$ & $71.28 \pm 3.545$ & $50.34 \pm 5.403^{\mathrm{a}}$ \\
Serum IL-6 $(\mathrm{pg} / \mathrm{ml})$ & $1.141 \pm 0.0871^{\mathrm{b}}$ & $2.063 \pm 0.2744$ & $1.131 \pm 0.0842^{\mathrm{b}}$ \\
Serum MCP-1 $(\mathrm{pg} / \mathrm{ml})$ & $47.56 \pm 5.594^{\mathrm{a}}$ & $72.47 \pm 3.848$ & $49.01 \pm 4.671^{\mathrm{a}}$
\end{tabular}

Statistical differences between groups were identified using a one-way ANOVA test followed by Tukey's multiple comparison test, $\mathrm{n}=12$ per group. All data in the table are presented as the mean \pm standard error of mean. ${ }^{\mathrm{a}} \mathrm{P}<0.05,{ }^{\mathrm{b}} \mathrm{P}<0.01$ and ${ }^{\mathrm{c}} \mathrm{P}<0.001$, vs. the HFD model group. C, cholesterol; TG, triglycerides; HDL, high-density lipoprotein; LDL, low-density lipoprotein; TNF- $\alpha$, tumor necrosis factor- $\alpha$; IL-6, interleukin-6; MCP-1, monocyte chemotactic protein-1; ND, normal diet; HFD, high fat diet; CQR, combination of quercetin and resveratrol.

CQR treatment reduces insulin and leptin levels in serum. HFD significantly elevated serum insulin and leptin levels but lowered the serum adipinectin levels compared with the ND (Table I). CQR significantly decreased serum insulin and leptin levels but exhibited no significant effect on serum adipinectin compared with the HFD group.

CQR suppresses the clustering of mast cells in adipose tissue. During the formation of HFD induced-obesity and exacerbation of adipose tissue inflammation or insulin resistance, a large amount of mast cells infiltrate the adipose tissue (17). It was reported that HFD induced mast cell clustering in WAT and promoted obesity and insulin resistance (18), while quercetin suppresses the release of cytokines from mast cells in vitro and obesity mice $(16,19)$. The number of mast cells in EAT was calculated to evaluate the effects of CQR on mast cell in adipose tissue of HFD-induced rats (Fig. 2). The results demonstrated that HFD significantly promoted the transition of mast cells into EATs, while CQR significantly reversed this effect (both $\mathrm{P}<0.05$ ).

CQR suppresses proinflammatory cytokines. A variety of proinflammatory cytokines are secreted by hypertrophic adipocytes and cause inflammatory cell infiltration during the development and progression of obesity (20). Several important proinflammatory cytokines involved in insulin resistance were detected in this study; results from ELISA determined that levels of the proinflammatory cytokines TNF- $\alpha$, IL- 6 and MCP-1, which increased in rats on a HFD, were significantly suppressed by CQR (Table I). These results suggest that CQR may relieve systematic inflammation induced by obesity.

CQR upregulates the AMPKa1/SIRT1 signalling pathway. AMPK $\alpha 1$ and SIRT1 are two key nutrient sensors linking nutrient metabolism and inflammation (21-22). AMPK $\alpha 1$ negatively regulates lipid-induced inflammation, which acts through SIRT1 to protect against obesity, inflammation and insulin resistance (23). It has been demonstrated that quercetin

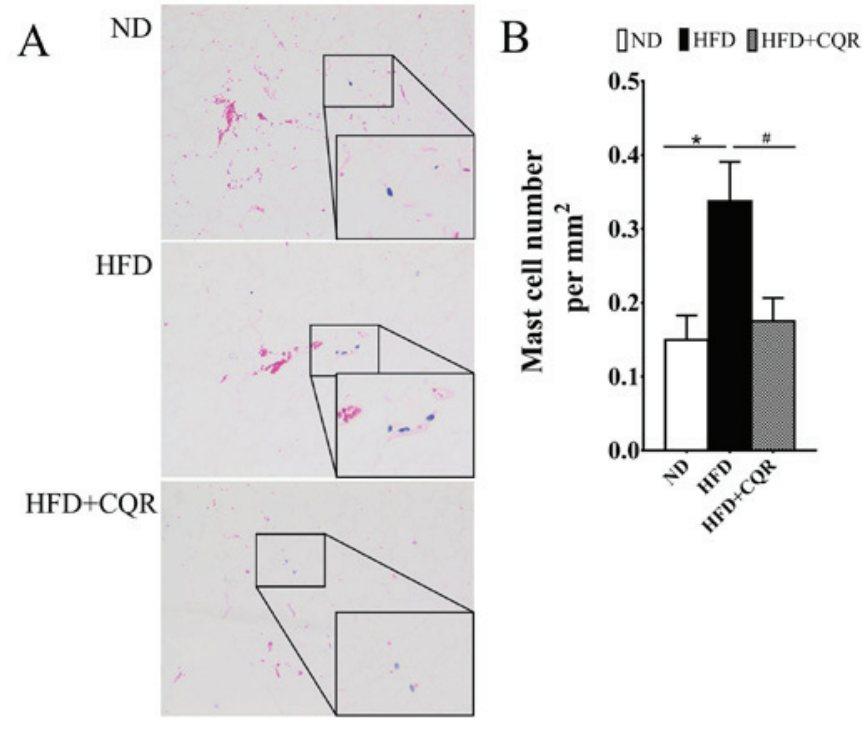

Figure 2. Treatment with CQR reduces the clustering of mast cells in the epididymal adipose tissue (EAT). At 11 weeks, tissue samples were collected and (A) epididymal white adipose tissue was observed using a light microscope (small box: magnification, x200, big box: magnification, $\mathrm{x} 100$ ) following toluidine blue staining of the mast cells indicated by the blue stain. Pink plaques are erythrocytes and leukocytes in the blood vessels of EAT. Erythrocytes are cells without a nucleus, while leukocytes are cells with a nucleus. (B) Quantification of mast cells in the indicated groups was performed by observing the slides, $\mathrm{n}=8$ per group. ${ }^{*} \mathrm{P}<0.05$ and ${ }^{\#} \mathrm{P}<0.05$. All data are presented as the mean \pm standard error of mean. $\mathrm{CQR}$, combination of quercetin and resveratrol; HFD, high fat diet; ND, normal diet.

alleviates obesity-associated adipose tissue macrophage infiltration and inflammation in mice via the AMPK $\alpha 1 /$ SIRT1 signaling pathway (16). Resveratrol also induces beneficial effects on obesity and metabolic disturbances by activating the AMPKa1/SIRT1 signaling pathway (24). Consistent with previous studies, AMPK $\alpha 1$ phosphorylation (Fig. 3A) and SIRT1 expression (Fig. 3B) in the EAT of rats fed a HFD were significantly suppressed. Treatment with CQR significantly 
$\mathbf{A}$

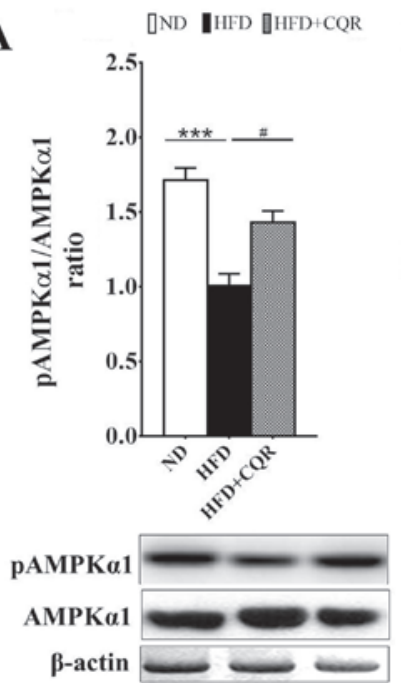

B

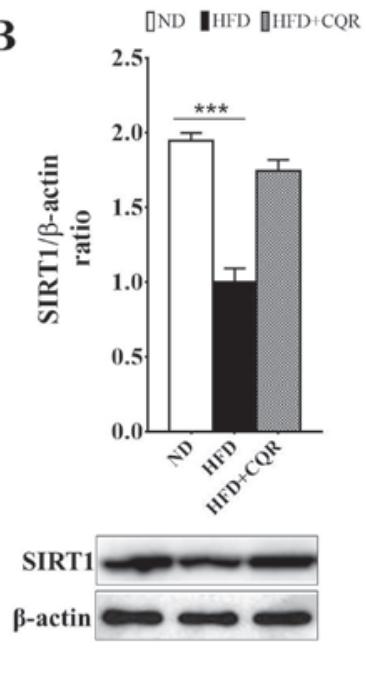

Figure 3. Treatment with CQR increases AMPK $\alpha 1$ phosphorylation and SIRT1 expression in the EAT of rats fed a HFD. After 11 weeks, tissue samples were obtained from each group and the (A) protein and phosphorylation levels of AMPK $\alpha 1$ and (B) the protein expression of SIRT1 in EATs, were measured. Quantification of AMPK $\alpha 1$ activity and SIRT1 expression was presented as the ratio of pAMPK $\alpha 1$ to total AMPK $\alpha 1$ and SIRT1 to $\beta$-actin, respectively. Statistical differences between groups were identified using a one-way ANOVA test followed by Tukey's multiple comparison test ( $\mathrm{n}=8$ per group). All data are presented as the mean \pm standard error of mean ${ }^{* * * *} \mathrm{P}<0.001$ and ${ }^{\#} \mathrm{P}<0.05$. AMPK $\alpha 1,5$ '-adenosine monophosphate-activated protein kinase $\alpha 1$; SIRT1, sirtuin 1; EAT, epididymal adipose tissue; HFD, high fat diet; ND, normal diet; CQR, combination of quercetin and resveratrol; p, phosphorylated.

reversed the suppression of AMPK $\alpha 1$ phosphorylation in a rat model (Fig. 3A).

\section{Discussion}

Quercetin and resveratrol are two types of dietary polyphenols, which may have beneficial effects on metabolic syndrome (25-33). It has also been reported that quercetin and resveratrol have a therapeutic effect on triacylglycerol metabolism in WAT (25). The results of the present study suggest that the combination of quercetin and resveratrol ameliorate insulin resistance and adipose tissue inflammation in obese rats. Furthermore, CQR treatment was able to reverse the changes in AMPKa1 phosphorylation and SIRT1 expression that occur in adipose tissues. To the best of our knowledge, the current study is the first to demonstrate that $\mathrm{CQR}$ has synergic effects on body fat accumulation and adipose inflammation by activating the AMPK $\alpha 1 /$ SIRT1 signaling pathway.

Previous studies have demonstrated that resveratrol and quercetin may reduce body fat accumulation in animal models (26-31). In our previous study, CQR exhibited synergistic effects on a HFD-induced metabolic phenotype in mice (32). Since polyphenols are efficient, particularly at higher doses (33), doses of $120 \mathrm{mg} / \mathrm{kg} /$ day resveratrol and $240 \mathrm{mg} / \mathrm{kg} /$ day quercetin were used in the current study. These are similar to the doses used in other comparable studies performed in rodents $(31,34-36)$. The recommended dosage of quercetin and resveratrol in obesity or insulin-resistance studies remains controversial and it was reported that treatment with lower doses of resveratrol may activate SIRT1,

whereas higher doses activate AMPK in a SIRT1-independent manner (37). The doses of quercetin and resveratrol used in some studies are $30 \mathrm{mg} / \mathrm{kg} / \mathrm{day}$ and $15 \mathrm{mg} / \mathrm{kg} / \mathrm{day}$, respectively $(26,38)$. In addition, quercetin is considered to be safe as it does not induce carcinogenicity and genotoxicity following oral administration at high doses (up to $2,000 \mathrm{mg} / \mathrm{kg}$ ) (39). Lagouge et al (31) demonstrated that dietary treatment with 200 or $400 \mathrm{mg} / \mathrm{kg} / \mathrm{day}$ resveratrol, delivered in either chow or a HFD, significantly increased the aerobic capacity and resistance to HFD induced-obesity in mice.

The anti-obesity effects of quercetin and resveratrol on HFD-induced body weight gain remain controversial and negative results have been reported by several research groups (40-42). Similar to previous studies $(24,26,29,32,43)$, the results of the present study demonstrated that the body weight gain between weeks 9 and 11 in rats fed a HFD and treated with $\mathrm{CQR}$ was significantly attenuated compared with rats fed a HFD alone. Treatment with CQR also reduced the weights of renal adipose tissues and EATs, however it did not affect SAT weight or food and energy intake. CQR therefore appears to have a mild weight-reducing and visceral fat-reducing effect. Visceral adipose tissue is a proinflammatory endocrine tissue and may be responsible for the increased cardiometabolic risk that occurs as body mass index rises (44). Regardless of adiposity status, visceral adiposity is associated with an adverse cardiometabolic profile, including inflammation, insulin resistance and myocardial dysfunction, all of which are hallmarks of an 'obese' phenotype (44). In addition the current study demonstrated that, HFD-induced dyslipidemia caused an increase in total C, TGs and LDL-C and a decrease in HDL-C in the blood. Chaudhari et al (45) also reported that a HFD induced significant increases in total C, TG and LDL-C in the rat serum, whereas it reduced HDL-C in rat serum (41). In the present study, $\mathrm{CQR}$ treatment increased serum HDL-C and decreased serum TC, TG and LDL-C, demonstrating that $\mathrm{CQR}$ is able to reduce the effects of a HFD in a rat model of obesity, which is consistent with previous reports $(12,46-48)$.

Chronic low-grade adipose tissue inflammation serves an important role in the development of HFD-induced obesity and insulin resistance $(4,49,50)$. The proinflammatory or anti-inflammatory molecules abnormally secreted from obese adipose tissue are called adipokines and provide evidence that there is a direct association between obesity and systemic inflammation (51). The adipose tissue of obese individuals exhibits increased expression of proinflammatory adipokines, including TNF- $\alpha$, MCP- 1 and IL- 6 but a reduced expression of adiponectin (52). Systemic leptin is increased in animals fed a HFD or with inflammation and/or infection states and directly affects cytokine production (53); thus it was hypothesized that CQR may ameliorate the inflammation in adipose tissue induced by a HFD. The results of the current study demonstrated that CQR attenuates adipocyte growth in EAT and mast cell clustering into adipose tissues. In the serum, CQR treatment reduced leptin, as well as TNF- $\alpha$, MCP-1 and IL-6 levels.

To reveal the molecular mechanisms by which CQR attenuates obesity associated adipose tissue inflammation, two important nutrient sensors and inflammatory regulators in EAT were assessed in the current study; AMPK $\alpha 1$ and SIRT1 $(54,55)$. CQR significantly increased 
HFD-suppressed AMPK $\alpha 1$ phosphorylation and markedly increased SIRT1 expression in EATs, suggesting that CQR influences the AMPKa1/SIRT1 signaling pathway in adipose tissues. The AMPK $\alpha 1 /$ SIRT1 signaling pathway may be a novel cellular target due to its anti-inflammatory effects in adipocytes $(24,56)$. AMPK $\alpha 1$ activates SIRT1 and inhibits inflammation in macrophages (57); furthermore, AMPK $\alpha 1$ may inhibit the activation of the nuclear factor- $\kappa \mathrm{B}$ system, a key regulator of innate immunity and inflammation (55). Activation of AMPK $\alpha 1$ may suppress the synthesis of pro-inflammatory cytokines, such as IL-6 and IL-8, in adipocytes (58). Aminoimidazole-4-carboxami-deriboside, a pharmacological activator of AMPK $\alpha 1$, may inhibit inflammatory responses via AMPK $\alpha 1$-independent pathways, and reverse lipopolysaccharide and HFD-induced inflammation (55-59). Reduction of EAT SIRT1 expression may induce ectopic inflammatory gene expression and the overexpression of SIRT1 inhibits HFD-induced increases in inflammation in adipose tissue (60). Dong et al (16) reported that dietary quercetin suppressed adipose tissue macrophage infiltration and inflammation via the AMPK $\alpha 1 /$ SIRT1 pathway in mice fed a HFD. Furthermore, Bitterman and Chung (61) reported that the AMPK $\alpha 1 /$ SIRT1 signaling pathway is the primary target for the metabolic effects of resveratrol.

In conclusion, the results of the present study suggest that CQR ameliorates not only excessive body weight gain and dyslipidemia, but also adipose tissue inflammation in rats with HFD-induced obesity. The anti-obese effect of CQR is associated with a reduction in body weight gain, adipocyte diameter, adipose tissue weight and an improvement of dyslipidemia in serum. Its anti-obese effect is closely associated with its anti-inflammation effects by which it reduces adipokine secretion and activates the AMPK $\alpha 1 /$ SIRT1 signaling pathway. These results indicate that CQR has the potential to reduce HFD-induced obesity and inflammation.

\section{Acknowledgements}

The present study was supported by the Education Department of Guizhou Province 1 (grant no. 2014-31), the Scientific and Technologic Innovated Team of Guizhou Province 2 (grant no. 2015-4025), the High-level Innovation Talents 3 (grant no. 2015-4029), the Teacher Development Project of Shanghai Municipal Education Commission and the Innovation Project of Amway (China) Research and Development Center Ltd., Co.

\section{References}

1. Wensveen FM, Valentić S, Šestan M, Turk Wensveen T and Polić B: The 'Big Bang' in obese fat: Events initiating obesity-induced adipose tissue inflammation. Eur J Immunol 45: 2446-2456, 2015.

2. van der Heijden RA, Sheedfar F, Morrison MC, Hommelberg PP, Kor D, Kloosterhuis NJ, Gruben N, Youssef SA, de Bruin A, Hofker MH, et al: High-fat diet induced obesity primes inflammation in adipose tissue prior to liver in C57BL/6j mice. Aging (Albany NY) 7: 256-268, 2015.

3. Ronti T, Lupattelli G and Mannarino E: The endocrine function of adipose tissue: An update. Clin Endocrinol (Oxf) 64: 355-365, 2006.

4. Ouchi N, Parker JL, Lugus JJ and Walsh K: Adipokines in inflammation and metabolic disease. Nat Rev Immunol 11: 85-97, 2011.
5. Brito AF, Ribeiro M, Abrantes AM, Pires AS, Teixo RJ, Tralhão JG and Botelho MF: Quercetin in cancer treatment, alone or in combination with conventional therapeutics? Curr Med Chem 22: 3025-3039, 2015

6. Chiow KH, Phoon MC, Putti T, Tan BK and Chow VT: Evaluation of antiviral activities of Houttuynia cordata Thunb. Extract, quercetin, quercetrin and cinanserin on murine coronavirus and dengue virus infection. Asian Pac J Trop Med 9: 1-7, 2016.

7. Boots AW, Haenen GR and Bast A: Health effects of quercetin: From antioxidant to nutraceutical. Eur J Pharmacol 585: 325-327, 2008.

8. Eid HM and Haddad PS: The antidiabetic potential of quercetin: Underlying mechanisms. Curr Med Chem 24: 355-364, 2017.

9. Li Y, Yao J, Han C, Yang J, Chaudhry MT, Wang S, Liu H and Yin Y: Quercetin, inflammation and immunity. Nutrients 8: 167, 2016.

10. Corrêa RCG, Peralta RM, Haminiuk CWI, Maciel GM, Bracht A and Ferreira ICFR: New phytochemicals as potential human anti-aging compounds: Reality, promise, and challenges. Crit Rev Food Sci Nutr 13: 1-16, 2016.

11. Pashevin DA, Tumanovska LV, Dosenko VE, Nagibin VS, Gurianova VL and Moibenko AA: Antiatherogenic effect of quercetin is mediated by proteasome inhibition in the aorta and circulating leukocytes. Pharmacol Rep 63: 1009-1018, 2011.

12. Nabavi SF, Russo GL, Daglia M and Nabavi SM: Role of quercetin as an alternative for obesity treatment: You are what you eat! Food Chem 179: 305-310, 2015.

13. Aguirre L, Fernández-Quintela A, Arias N and Portillo $\mathrm{M}$ : Resveratrol: Anti-obesity mechanisms of action. Molecules 19: 18632-18655, 2014.

14. National Research Council (US) Committee for the Update of the Guide for the Care and Use of Laboratory Animals: Guide for the Care and Use of Laboratory Animals. 8th edition. National Academies Press (US), Washington, DC, 2011.

15. Altintas MM, Azad A, Nayer B, Contreras G, Zaias J, Faul C, Reiser $\mathbf{J}$ and Nayer A: Mast cells, macrophages, and crown-like structures distinguish subcutaneous from visceral fat in mice. J Lipid Res 52: 480-488, 2011.

16. Dong J, Zhang X, Zhang L, Bian HX, Xu N, Bao B and Liu J: Quercetin reduces obesity-associated ATM infiltration and inflammation in mice: A mechanism including AMPK $\alpha 1 /$ SIRT1. J Lipid Res 55: 363-374, 2014.

17. Sun S, Ji Y, Kersten S and Qi L: Mechanisms of inflamatory responses in obese adipose tissue. Annu Rev Nutr 32: 261-286, 2012.

18. Liu J, Divoux A, Sun J, Zhang J, Clément K, Glickman JN, Sukhova GK, Wolters PJ, Du J, Gorgun CZ, et al: Genetic deficiency and pharmacological stabilization of mast cells reduce diet-induced obesity and diabetes in mice. Nat Med 15: 940-945, 2009.

19. Park HH, Lee S, Son HY, Park SB, Kim MS, Choi EJ, Singh TS, Ha JH, Lee MG, Kim JE, et al: Flavonoids inhibit histamine release and expression of proinfl ammatory cytokines in mast cells. Arch Pharm Res 31: 1303-1311, 2008.

20. Lee WH, Lin RJ, Lin SY, Chen YC, Lin HM and Liang YC: Osthole enhances glucose uptake through activation of AMP-activated protein kinase in skeletal muscle cells. J Agric Food Chem 59: 12874-12881, 2011.

21. Sag D, Carling D, Stout RD and Suttles J: Adenosine 5'-monophosphate-activated protein kinase promotes macrophage polarization to an anti-inflammatory functional phenotype. J Immunol 181: 8633-8641, 2008.

22. Yoshizaki T, Milne JC, Imamura T, Schenk S, Sonoda N, Babendure JL, Lu JC, Smith JJ, Jirousek MR and Olefsky JM: SIRT1 exerts anti-inflammatory effects and improves insulin sensitivity in adipocytes. Mol Cell Biol 29: 1363-1374, 2009.

23. Yang Z, Kahn BB, Shi H and Xue BZ: Macrophage alpha1 AMP-activated protein kinase (alpha1AMPK) antagonizes fatty acid-induced inflammation through SIRT1. J Biol Chem 285: 19051-19059, 2010.

24. De Ligt M, Timmers S and Schrauwen P: Resveratrol and obesity: Can resveratrol relieve metabolic disturbances? Biochim Biophys Acta 1852: 1137-1144, 2015.

25. Arias N, Macarulla MT, Aguirre L, Milton I and Portillo MP: The combination of resveratrol and quercetin enhances the individual effects of these molecules on triacylglycerol metabolism in white adipose tissue. Eur J Nutr 55: 341-348, 2016.

26. Gómez-Zorita S, Fernández-Quintela A, Macarulla MT Aguirre L, Hijona E, Bujanda L, Milagro F, Martínez JA and Portillo MP: Resveratrol attenuates steatosis in obese Zucker rats by decreasing fatty acid availability and reducing oxidative stress. Br J Nutr 107: 202-210, 2012. 
27. Rivera L, Morón R, Sánchez M, Zarzuelo A and Galisteo M: Quercetin ameliorates metabolic syndrome and improves the inflammatory status in obese Zucker rats. Obesity Silver (Spring) 16: 2081-2087, 2008.

28. Jung CH, Cho I, Ahn J, Jeon TI and Ha TY: Quercetin reduces high-fat diet-induced fat accumulation in the liver by regulating lipid metabolism genes. Phytother Res 27: 139-143, 2013.

29. Kobori M, Masumoto S, Akimoto $\mathrm{Y}$ and Oike $\mathrm{H}$ : Chronic dietary intake of quercetin alleviates hepatic fat accumulation associated with consumption of a Western-style diet in C57/BL6J mice. Mol Nutr Food Res 55: 530-540, 2011.

30. Alberdi G, Rodríguez VM, Miranda J, Macarulla MT, Arias N, Andrés-Lacueva C and Portillo MP: Changes in white adipose tissue metabolism induced by resveratrol in rats. Nutr Metab (Lond) 8: 29, 2011

31. Lagouge M, Argmann C, Gerhart-Hines Z, Meziane H, Lerin C, Daussin F, Messadeq N, Milne J, Lambert P, Elliott P, et al: Resveratrol improves mitochondrial function and protects against metabolic disease by activating SIRT1 and PGC-1alpha. Cell 127: 1109-1122, 2006

32. Zhou M, Wang S, Zhao A, Wang K, Fan Z, Yang H, Liao W, Bao S, Zhao L, Zhang Y, et al: Transcriptomic and metabonomic profiling reveal synergistic effects of quercetin and resveratrol supplementation in high fat diet fed mice. J Proteome Res 11: 4961-4971, 2012

33. Amiot MJ, Riva C and Vinet A: Effects of dietary polyphenols on metabolic syndrome features in humans: A systematic review. Obes Rev 17: 573-586, 2016.

34. Andrade JM, Frade AC, Guimarães JB, Freitas KM, Lopes MT, Guimarães AL, de Paula AM, Coimbra CC and Santos SH: Resveratrol increases brown adipose tissue thermogenesis markers by increasing SIRT1 and energy expenditure and decreasing fat accumulation in adipose tissue of mice fed a standard diet. Eur J Nutr 53: 1503-1510, 2014

35. Wu Z, Zhao J, Xu H, Lyv Y, Feng X, Fang Y and Xu Y: Maternal quercetin administration during gestation and lactation decrease endoplasmic reticulum stress and related inflammation in the adult offspring of obese female rats. Eur J Nutr 53: 1669-1683, 2014.

36. Liu H, Guo X, Chu Y and Lu S: Heart protective effects and mechanism of quercetin preconditioning on anti-myocardial ischemia reperfusion (IR) injuries in rats. Gene 545: 149-155, 2014.

37. Price NL, Gomes AP, Ling AJ, Duarte FV, Martin-Montalvo A North BJ, Agarwal B, Ye L, Ramadori G, Teodoro JS, et al: SIRT1 is required for AMPK activation and the beneficial effects of resveratrol on mitochondrial function. Cell Metab 15 675-690, 2012

38. Arias N, Macarulla MT, Aguirre L, Miranda J and Portillo MP: Liver delipidating effect of a combination of resveratrol and quercetin in rats fed an obesogenic diet. J Physiol Biochem 71: $569-576,2015$

39. Harwood M, Danielewska-Nikiel B, Borzelleca JF, Flamm GW, Williams GM and Lines TC: A critical review of the data related to the safety of quercetin and lack of evidence of in vivo toxicity, including lack of genotoxic/carcinogenic properties. Food Chem Toxicol 45: 2179-2205, 2007.

40. Panchal SK, Poudyal H and Brown L: Quercetin ameliorates cardiovascular, hepatic, and metabolic changes in diet-induced metabolic syndrome in rats. J Nutr 142: 1026-1032, 2012.

41. Boesch-Saadatmandi C, Wagner AE, Wolffram S and Rimbach G: Effect of quercetin on inflammatory gene expression in mice liver in vivo-role of redox factor 1, miRNA-122 and miRNA-125b. Pharmacol Res 65: 523-530, 2012.

42. Pan QR, Ren YL, Zhu JJ, Hu YJ, Zheng JS, Fan H, Xu Y, Wang G and Liu WX: Resveratrol increases nephrin and podocin expression and alleviates renal damage in rats fed a high-fat diet. Nutrients 6: 2619-2631, 2014

43. Peredo-Escárcega AE, Guarner-Lans V, Pérez-Torres I, Ortega-Ocampo S, Carreón-Torres E, Castrejón-Tellez V, Díaz-Díaz E and Rubio-Ruiz ME: The combination of resveratrol and quercetin attenuates metabolic syndrome in rats by modifying the serum fatty acid composition and by upregulating SIRT1 and SIRT2 expression in white adipose tissue. Evid Based Complement Alternat Med 2015: 474032, 2015.
44. Bays HE: Adiposopathy is 'sick fat' a cardiovascular disease? J Am Coll Cardiol 57: 2461-2473, 2011.

45. Chaudhari HS, Bhandari U and Khanna G: Preventive effect of embelin from embelia ribes on lipid metabolism and oxidative stress in high-fat diet-induced obesity in rats. Planta Med 78: 651-657, 2012.

46. Franco JG, Lisboa PC, Lima NS, Amaral TA, Peixoto-Silva N, Resende AC, Oliveira E, Passos MC and Moura EG: Resveratrol attenuates oxidative stress and prevents steatosis and hypertension in obese rats programmed by early weaning. J Nutr Biochem 24: 960-966, 2013.

47. Baek SH, Chung HJ, Lee HK, D'Souza R, Jeon Y, Kim HJ, Kweon SJ and Hong ST: Treatment of obesity with the resveratrol-enriched rice DJ-526. Sci Rep 4: 3879, 2014.

48. D'Andrea G: Quercetin: A flavonol with multifaceted therapeutic applications? Fitoterapia 106: 256-271, 2015.

49. Sun S, Ji Y, Kersten S and Qi L: Mechanisms of inflammatory responses in obese adipose tissue. Annu Rev Nutr 32: 261-286, 2012.

50. Osborn $\mathrm{O}$ and Olefsky JM: The cellular and signaling networks linking the immune system and metabolism in disease. Nat Med 18: 363-374, 2012.

51. Berg AH and Scherer PE: Adipose tissue, inflammation, and cardiovascular disease. Circ Res 13: 939-949, 2005.

52. Weisberg SP, McCann D, Desai M, Rosenbaum M, Leibel RL and Ferrante AW Jr: Obesity is associated with macrophage accumulation in adipose tissue. J Clin Investig 112: 1796-1808, 2003.

53. Fantuzzi $G$ and Faggioni R: Leptin in the regulation of immunity, inflammation, and hematopoiesis. J Leukoc Biol 68: 437-446, 2000.

54. Weng SY and Schuppan D: AMPK regulates macrophage polarization in adipose tissue inflammation and NASH. J Hepatol 58: 619-621, 2013.

55. Salminen A, Hyttinen JM and Kaarniranta K: AMP-activated protein kinase inhibits $\mathrm{NF}-\kappa \mathrm{B}$ signaling and inflammation: Impact on healthspan and lifespan. J Mol Med (Berl) 89: 667-676, 2011.

56. Eo H, Jeon YJ, Lee M and Lim Y: Brown Alga Ecklonia cava polyphenol extract ameliorates hepatic lipogenesis, oxidative stress, and inflammation by activation of AMPK and SIRT1 in high-fat diet-induced obese mice. J Agric Food Chem 63: 349-359, 2015.

57. Yang Z, Kahn BB, Shi H and Xue BZ: Macrophage alpha1 AMP-activated protein kinase (alpha1AMPK) antagonizes fatty acid-induced inflammation through SIRT1. J Biol Chem 285 : 19051-19059, 2011

58. Grisouard J, Dembinski K, Mayer D, Keller U, Müller B and Christ-Crain M: Targeting AMP-activated protein kinase in adipocytes to modulate obesity-related adipokine production associated with insulin resistance and breast cancer cell proliferation. Diabetol Metab Syndr 3: 16, 2011.

59. Łabuzek K, Liber S, Gabryel B and Okopień B: AICAR (5-aminoimidazole-4-carboxamide-1-beta-4-ribofuranoside) increases the production of toxic molecules and affects the profile of cytokines release in LPS-stimulated rat primary microglial cultures. Neurotoxicology 31: 134-146, 2010.

60. Gillum MP, Kotas ME, Erion DM, Kursawe R, Chatterjee P, Nead KT, Muise ES, Hsiao JJ, Frederick DW, Yonemitsu S, et al: SirT1 regulates adipose tissue inflammation. Diabetes 60 : 3235-3245, 2011

61. Bitterman JL and Chung JH: Metabolic effects of resveratrol: Addressing the controversies. Cell Mol Life Sci 72: 1473-1488, 2015. 